\title{
Large Electroencephalographic Responses and Their Relationship to Cleido-Cranial Dysplasia
}

\author{
ADRIAN UPTON*, SARAH BUNDEY** and SUSAN SANDERS
}

SUMMARY: We have reported six individuals (five certain heterozygotes for cleido-cranial-dysostosis and one possible heterozygote) who have unusual EEG findings, consisting of very large responses to photic flash stimulation at very low stimulus rates.

Such visual responses are extremely rare and have not been seen before in the experience of an EEG department over 12 years and they were not seen in 98 control subjects. It is likely that these responses are an irregular mani-

RÉSUMÉ: Nous avons rapporté six sujets (5 sont hétérozygotes certains pour la dysostose cléido-crânienne et I est possiblement hétérozygote) qui ont des EEG peu communs, consistant en des réponses massives à la stimulation photolumineuse à des degrés de stimulus très bas.

De telles réponses visuelles sont extrêmement rares et n'ont pas été vues auparavant dans un département d'EEG de 12 ans d'existence, et sont absentes chez les 98 sujets contrôles. ll est vraisemblable que ces réponses festation of the gene for cleido-cranialdysplasia, and that the responses are independent of skull deformity. One importance of these responses is their demonstration in neurologically normal individuals for previously such large responses have only been reported in association with neurolipidosis. They may have neurophysiological significance in that they may reflect an unusual balance between inhibitory and excitatory mechanisms in the nervous system.

soient une manifestation irrégulière du gène de la dysostose cléido-crânienne et que les réponses soient indépendantes de la difformité du crâne. L'importance de ces réponses est leur démonstration chez des individus neurologiquement normaux. Auparavant de telles réponses n'ont été rapporté qu'en association avec la neurolipidose. Elles peuvent avoir une signification neurophysiologique pouvant réfléter une balance peu commune entre les mécanismes inhibiteurs et excitateurs dans le système nerveux.
From: The National Hospitals for Nervous Diseases, Queen Square, London, W.C.1.

*Department of Medicine (Neurology), McMaster University, Hamilton, Ontario.

**M.R.C. Clinical Genetics Unit, Institute of Child Health, WEIN, 1 EH.

Reprint requests to Dr. A. R. M. Upton, Department of Medicine (Neurology), McMaster University, 1200 Main St. West, Hamilton L8S $4 \mathrm{~J} 9$. Ontario, Canada.
The EEG responses to rhythmic photic stimulation were first investigated in 1934 (Adrian and Matthews, 1934). Now photic flash stimuli are usually administered as part of a routine EEG recording. With single stimuli, or at low rates of stimulation, the main component of the EEG response is an electropositive wave over the occipital region at a latency of 70-90 msec after each flash stimulus (Cobb and Dawson, 1960). With the eyes open the amplitude of the responses is usually maximal at a stimulus rate of 8-13 $\mathrm{c} / \mathrm{sec}$ (Kiloh and Osselton, 1966) and a weak correlation between the amplitudes of alpha wave and visual evoked potentials has been reported (Kooi and Bagchi, 1964; Weinman, Creutzfeldt and Heyde, 1964; Fenwick and Dollimore, 1969). Walter (1951) noted that visual evoked responses may be large at low stimulation frequencies, but very large responses (10 to 30 times normal) at low stimulus rates have been reported as diagnostic of neuronal lipidosis (Pampiglione and Lehovsky, 1968).

We have observed unusually large visually evoked potentials, particularly at low flicker frequencies, in a boy of 18 who had idiopathic epilepsy and cleido-cranial dysplasia. Because of this chance finding we investigated his relatives, a second family with cleido-cranial dysplasia and three sporadic cases of the same disorder. Besides the first patient, five further individuals without neurological symptoms or signs, were found to possess similarly large photic responses. This is the first time such electroencephalographic phenomena have been reported in neurologically normal people, and these unusual neurophysiological re- 


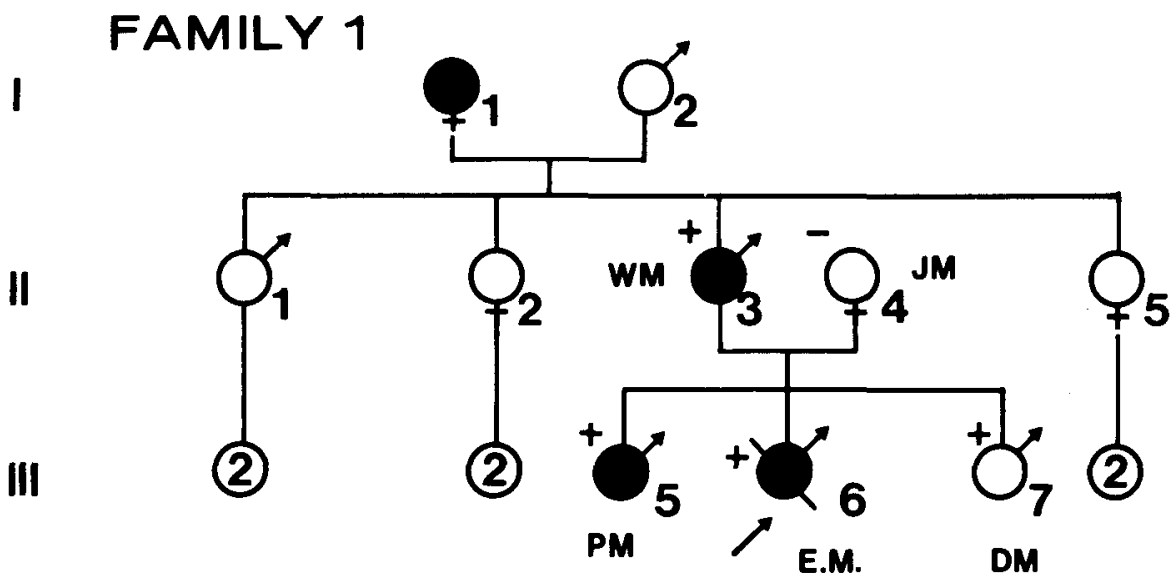

FAMILY 2

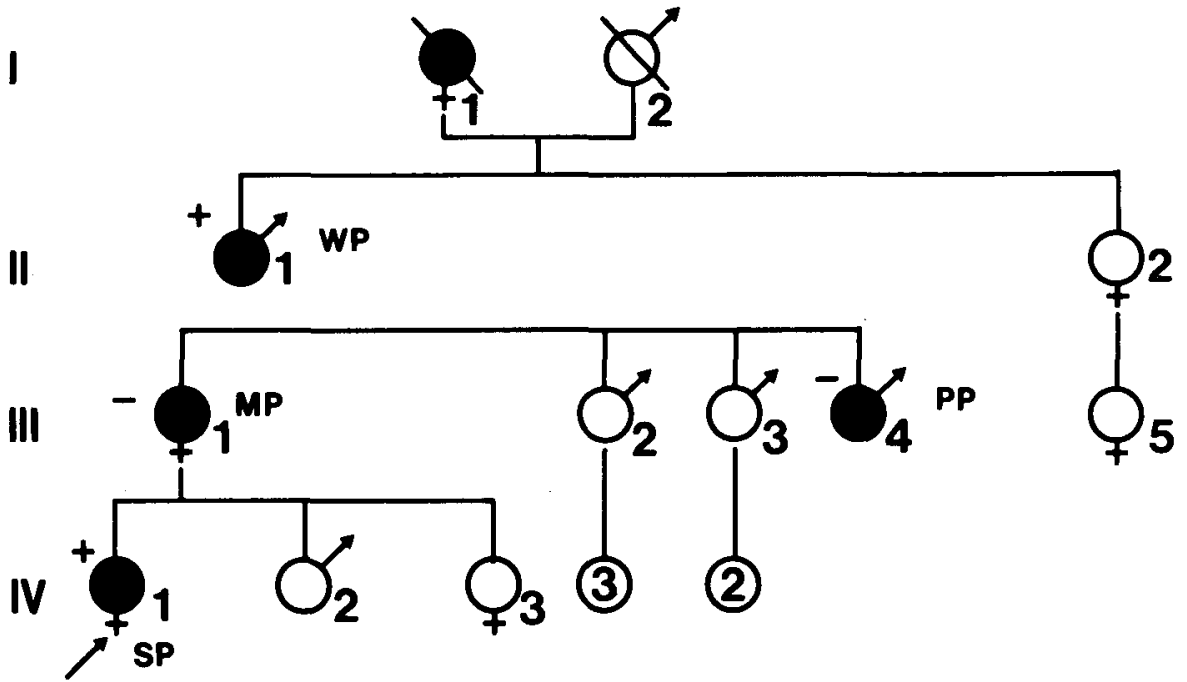

Figure 1-Families with both cleido-cranial dysplasia and large photic responses.

sults were seen in association with a condition which is not generally associated with any neurological problems (Penrose, 1963; Richards, 1969). Interest in these findings led us to chart the normal range of size of visual responses at different flicker frequencies in a series of policemen under the same conditions as the patients.

\section{RESULTS}

a) Clinical and Genetic Findings in Patients

Family 1

Family (Figure 1) was ascertained through III6 (E.M. b. 3.4.52) who first sought attention after one noctural grand-mal attack. Apart from a head injury with brief unconsciousness at the age of four, there was nothing relevant in his past history.
He was an intelligent boy and there were no abnormal neurological signs. He had, however, the clinical appearance of cleido-cranialdysplasia. His skull was wide, with flattening of the vertex and occiput, marked frontal bossing, and wide open anterior fontanelles. The clavicles appeared clinically absent but radiography revealed that a small part of the right was present. Radiography of the skull showed thickening of the vault with many wormian bones and abnormal sutures, an abnormally shaped skull base owing to relative smallness of the bones of the base, and a malformed maxilla and mandible with some malocclusion. Further radiology showed other features of cleido-cranial dysplasia, namely wedging of some vertebrae with a dorsal scoliosis, incomplete forma-
ONormal male

Normal female

$\otimes \times$ normal individuals

QDead

$\nearrow$ Propositus

Cleido-cranial

-dysostosis

+ Large photic responses on EEG.

- Normal photic responses on EEG. tion of pubic and ischio-pubic rami; delayed epiphyseal fusion in the hands with short poorly tufted terminal phalanges. Electroencephalogram showed no focal or epileptic activity. In view of the history and negative neurological findings the diagnosis was made of idiopathic epilepsy. The EEG did show, however, some unusual changes which will be discussed later.

The patient, III6, was put on a phenobarbitone and had only one further nocturnal epileptic attack during the next year. One morning he was found dead in bed, and was thought to have asphyxiated during a third epileptic attack. A coroner's post-mortem revealed no specific brain pathology but did show a marked "hot-cross bun" effect of the brain, as described in other pa- 


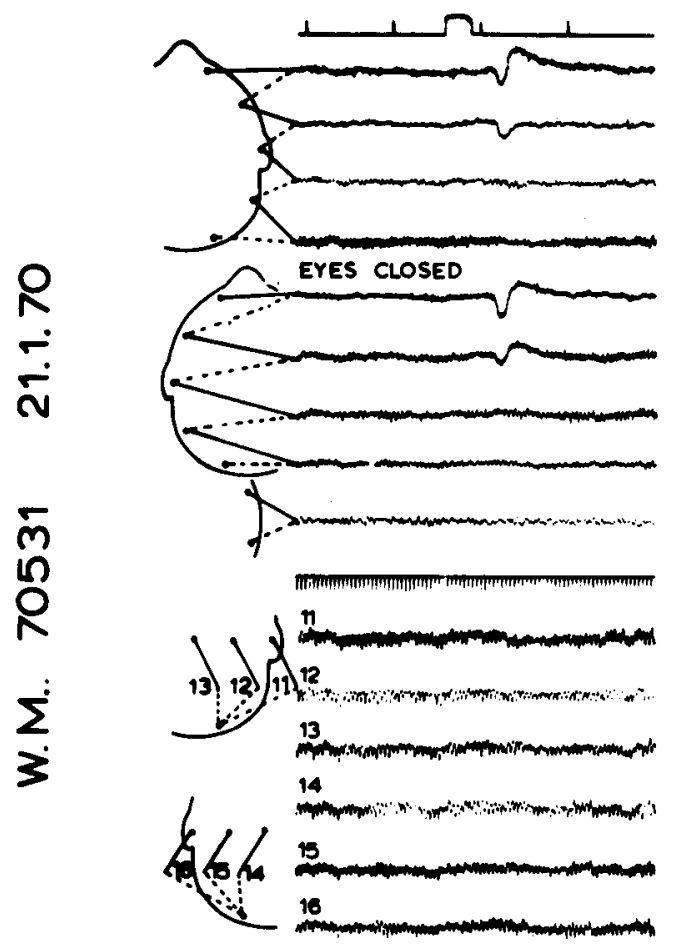

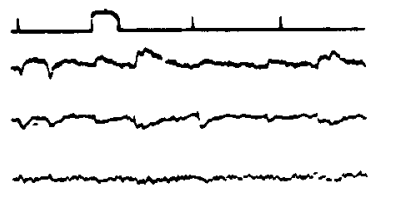

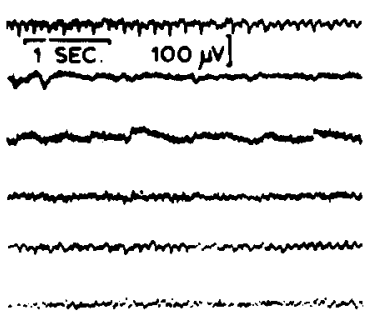

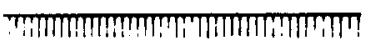

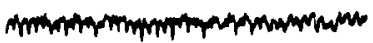

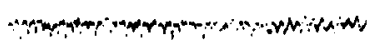

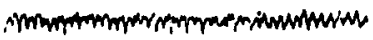

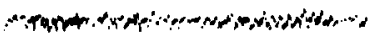

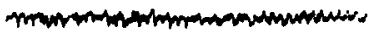

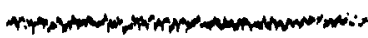
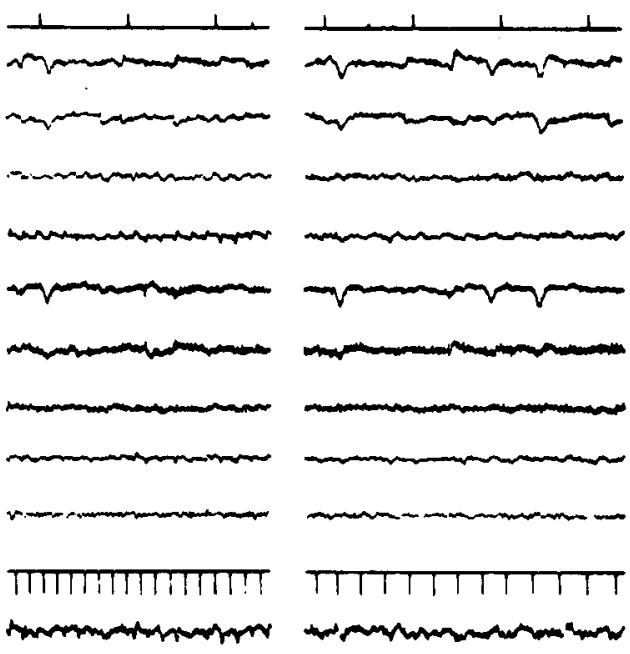

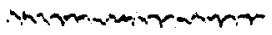

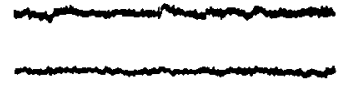

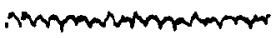

minnasingming

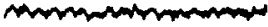

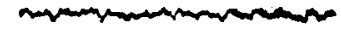
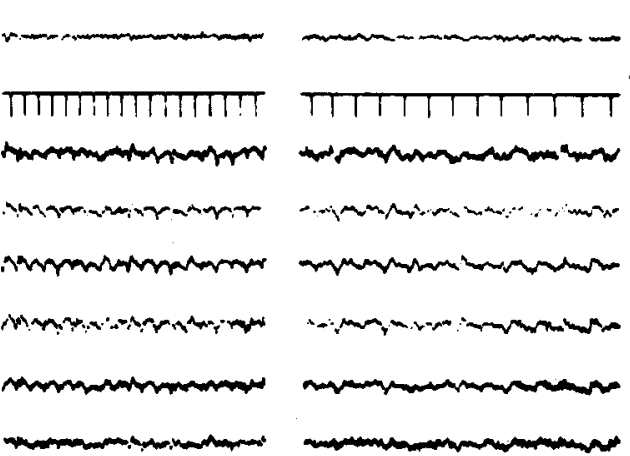

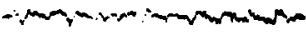

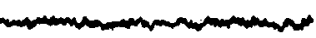

$\infty$
$\mathbb{1}$

0
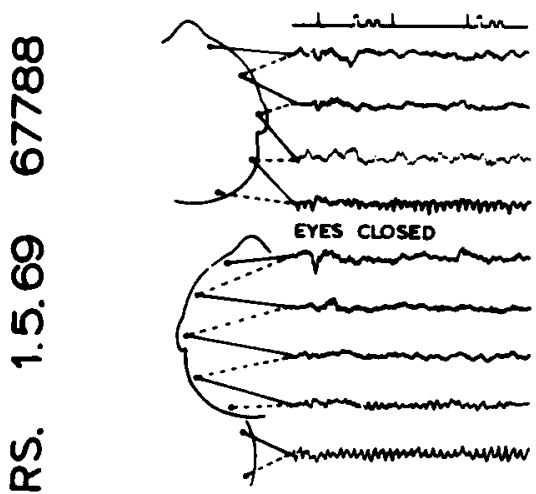

$\stackrel{2}{2}$

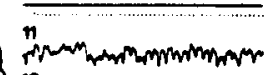

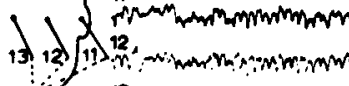

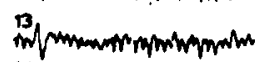
ij (5)
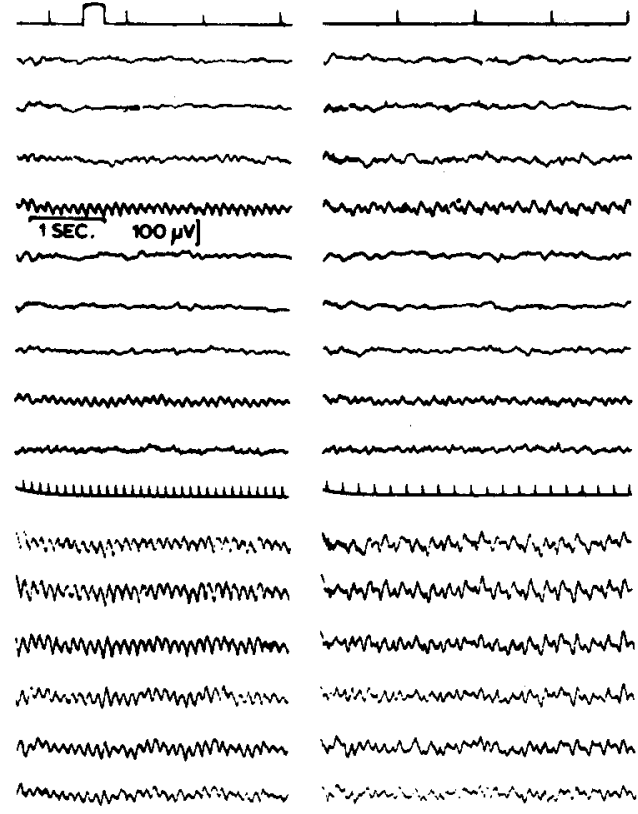

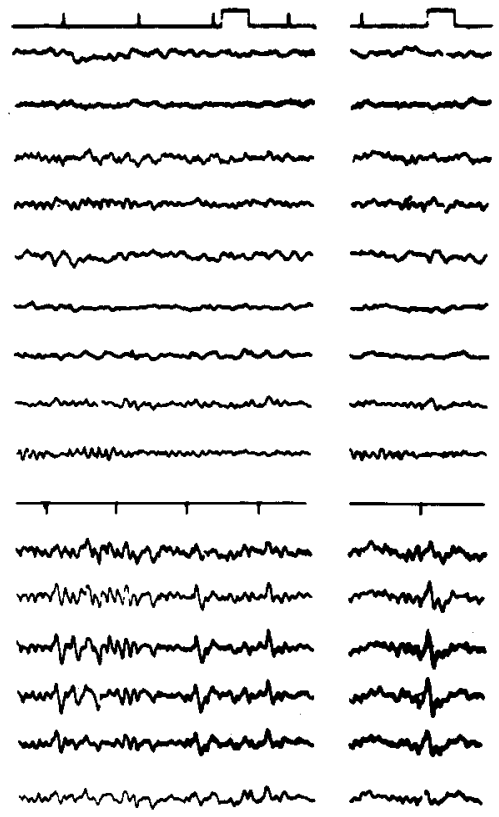

Figure 2-Photic flash responses in father (W.M.) and son (E.M.) at various flash frequencies showing high voltage responses at low rates of stimulation.

tients with cleido-cranial dysplasia.

His older brother, III5, (P.M. b. 21.4.49) also shows signs of cleidocranial-dy sostosis with obvious skull deformity. He is an intelligent healthy, young man, whose main symptoms in the past were related to severe bilateral coxa vara which had necessitated in-patient treatment.
The young brother, III7, (D.M. b. 11.12.53) has no skeletal abnormality and radiography of his skull and clavicles is normal. He is, however, educationally sub-normal, this mild degree of mental retardation being attributed to hypoxia at birth. The mother, $\mathrm{II}_{4}$, (J.M. b. 14.4.23) is healthy. The father, II3, (Fig. 3) (W.M. b. 24.1.23) has cleido-cranialdysplasia with skull and clavicular abnormalities. His main symptoms have been related to the presence of supernumary and malplaced teeth, most of which have been removed. The paternal grandmother, $\mathrm{I}_{1}$, (b. 31.13.1894) also has cleido-cranialdysplasia. 


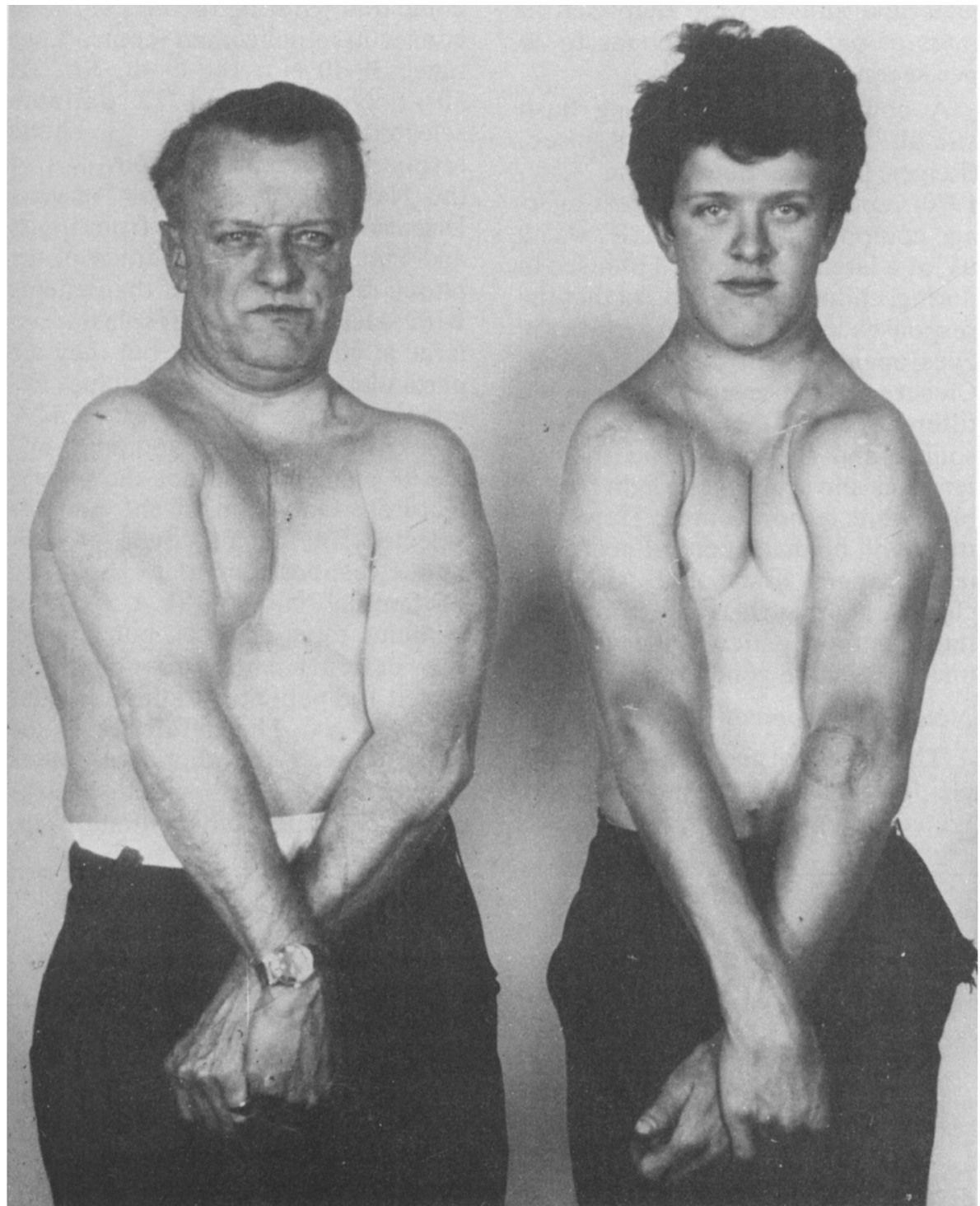

Figure 3-Father and son (Family 1). Physical features with absence of clavicles.

\section{Family 2}

Family 2 (Figure 1) was ascertained through IV, (S.P. b. 24.1.52) who attended a pediatric clinic in infancy because of failure to thrive. Skull and clavicular changes of cleido-cranial-dysostosis were noted, as were the signs of a patent ductus arteriosus which was successfully ligated. However, growth remained retarded and her short stature is her main disability in addition to some malerupted teeth. At 19 she is an intelligent girl only $4^{\prime} 9^{\prime \prime}$ tall: she has absent clavicles; her skull shape is normal although radiology reveals a wide anterior fontanelle and numerous wormian bones. Her two sibs are clinically normal, and her lateral halves of both clavicles are absent: he has a marked thoracic scoliosis; and radiology of his pelvis shows unusually narrow iliac bones. The father of III 1 and $\mathrm{IH}_{4}, \mathrm{II}_{1}$, (W.P. b. 8.3.01) is a short fit man whose main complaints in the past have been related to his spine. In 1953 he was found to have an L4-5 spondylolisthesis, and susequently a lumbar bone graft was carried out. He has absent clavicles, marked frontal bossing and brachycephaly of his skull but no increase in its transverse diameter.

\section{Isolated Cases}

Three further cases of cleidocranial-dysostosis were found after a search through the records of a pediatric hospital, an orthopedic hospital, and several dental departments. I.V. (b. 30.7.44) attended a pediatric clinic at the age of 10 on account of her short stature. From the age of 15 she has attended a dental clinic with unerupted teeth. She has no other symptoms. She is $4^{\prime} 4^{\prime \prime}$ in height. Her skull is normal but her clavicles are absent. Radiology of her pelvis shows an open pubic symphysis and abnormally shaped and underdeveloped ischia rami. Both her parents and two sisters are normal.

L.T., (b. 7.8.56), has no symptoms of cleido-cranial-dysplasia. His condition was recognized during hospital admission for poliomyelitis at the age of four. At 14 years he is $4^{\prime} 7^{\prime \prime}$ in height; his skull is wide and bossed with a large anterior fontanelle; his clavicles are absent. Radiology also shows changes in the pelvis of cleido-cranial-dysplasia. His parents were aged 40 and 43 at the time of his birth. His mother has no signs of cleido-cranial-dysostosis, but his father and three older sibs, though said to be normal, could not be examined. Two sibs died in infancy of unrelated causes.

The skeletal abnormality in the third patient, C.N. (b. 24.7.39), was recognized soon after birth, for he came under medical attention on account of cerebral palsy. His is of normal intelligence, is $5^{\prime} 7^{\prime \prime}$ in height, and his neurological abnormalities are confined to his left leg, which 
is short and spastic. In addition, he has a wide, bossed skull, no clavicles, and is attending a dental department on account of malerupted teeth. His parents and one older brother are normal.

\section{METHODS}

As the laboratory conditions such as positioning of electrodes, photic stimulator characteristics and amplification factors may influence the amplitude of evoked responses, it is important to compare patients and controls with the same equipment. Surface silver chloride button electrodes were applied with collodion in the 10-20 international configuration and these were connected to an Elema Schonander Mingograph 16 channel EEG machine. Flashes were delivered by a gas discharge tube $\mathrm{SU}$ 401 (P.T.W. Wiesbaden) at a maximum power of 4 watts with an energy of 0.29 joules per flash ( 380 volts $4 \mathrm{uV}$ ) The reflector was placed about 24 inches in front of the sub-

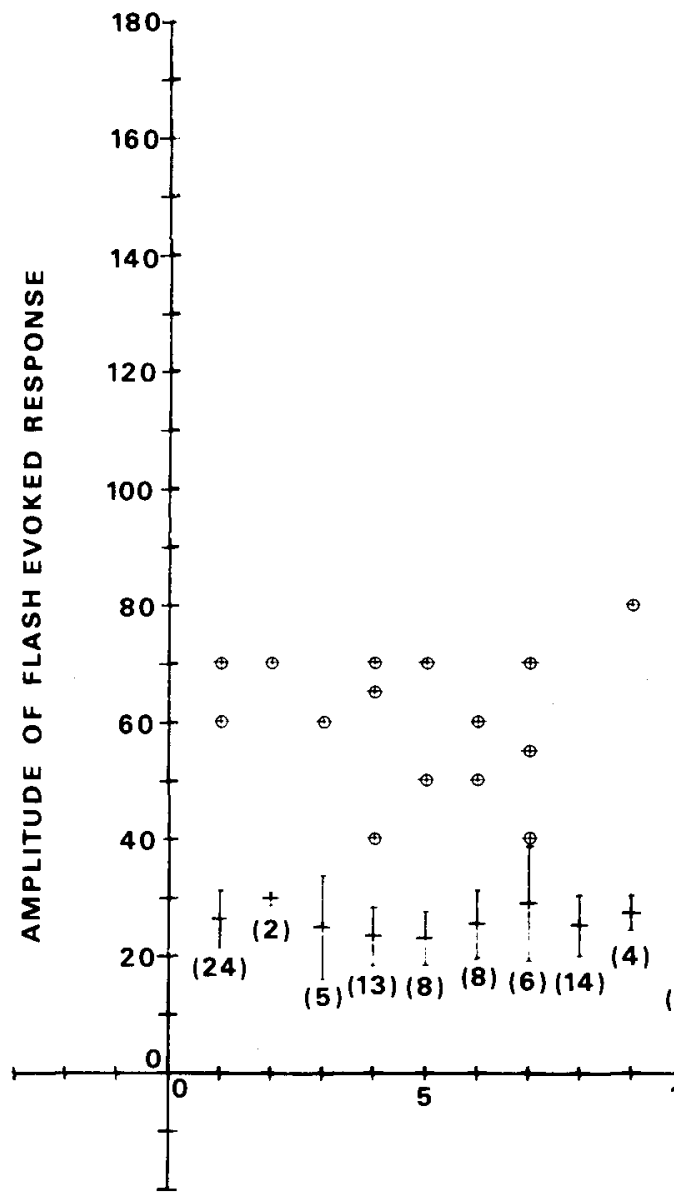

jects and stimuli were delivered at rates of one every 5 seconds to 30 per second.

A comparable study using flash stimuli at intervals of $768 \mathrm{msec}$. (Reiger, Lesevre, Rémond and Lairy, 1970) reported that the largest average component of the V.E.R. was 9 $\mathrm{uV}$ at a latency of about $110 \mathrm{msec}$ in normal children. They found that the responses were half as large with the eyes open as with the eyes closed. Closure of the eyes inserts a red filter (eyelids) between the light source and the retina and this attenuates and scatters the light from a blue-white xenon source. However, there will be many central neurological changes associated with eye closure and we therefore compared the results in patients and controls under the same conditions.

\section{Neurophysiological Results}

The results of the 10 patients with cleido-cranial dysplasia, an unaffected parent and one sibling were

\section{EYES OPEN}

compared with the records of the 98 consecutive policemen (controls age range $39-30$ No. $18,49-40$, No. 32 , $50+$, No. 48) and 12 patients selected for the size of their photic responses over the last ten years at the National Hospital for Nervous Diseases. It can be seen from Fig. 4 and Fig. 5 that the amplitude of the photic responses of 5 of the patients with cleido-cranial dysplasia are large at all frequencies, but they are particularly large at stimulus frequencies below $8 \mathrm{c} / \mathrm{s}$. (Fig. 5). Five cases, three of them sporadic, and the 98 policemen do not show these features. Only one of the patients selected for the amplitude of their photic responses overlaps the group of familial cases with C.C.D. at stimulus rates of $6 \mathrm{c} / \mathrm{s}$, but none of the patients show responses to match the patients at stimulus rates below $4 \mathrm{c} / \mathrm{s}$. The difference in the amplitudes of the photic responses between the C.C.D. patients and the others is greatest when stimuli were

\section{+ NORMAL \\ - PATIENTS}

THE NUMBER OF OBSERVATIONS IS IN PARENTHESIS.

Figure 4 - Mean amplitude of flash evoked response of normal group \pm confidence interval $P=0.05$ 


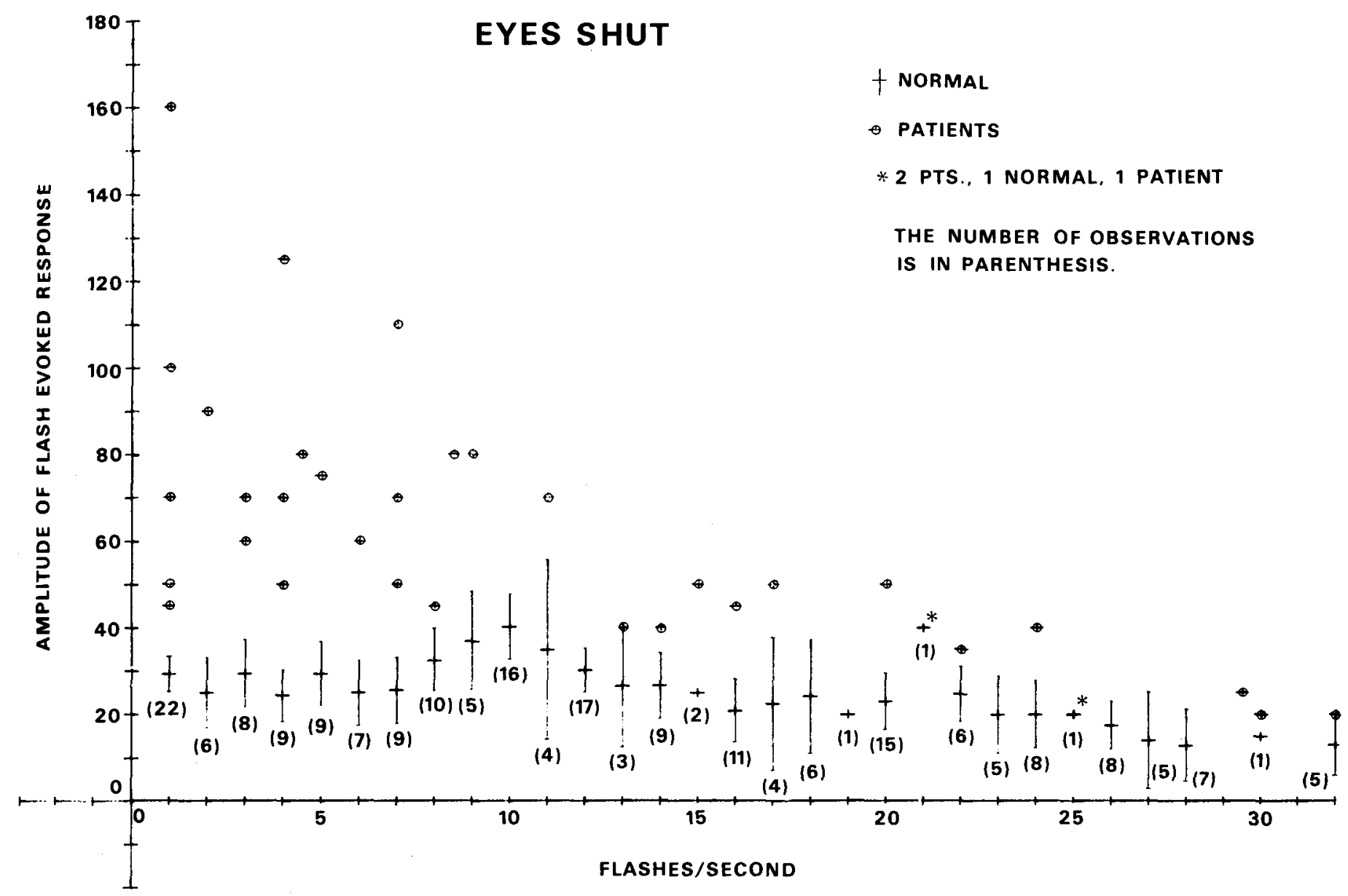

Figure $5-$ Mean amplitude of flash evoked response of normal group \pm confidence interval at $P=0.05$

presented with the eyes shut. At stimulus rates of $1 \mathrm{flash} / \mathrm{second}$ with the eyes closed the C.C.D. patients show responses which are $40 \%$ (P.M.) to $320 \%$ (E.M.) larger than the largest responses of the controls. A C.C.D. patient from a second family (S.P.) shows responses $100 \%$ larger than the controls.

The responses in Family 1 were very different when the massive flash stimulus was replaced with the reversible chequerboard pattern. The responses to reversal of the chequerboard were large, but they were not outside the normal limits for this laboratory. It is clear that accommodation was not the important difference as the flashes evoked the very large responses even when the patients were asked to focus on the lamp.

\section{DISCUSSION}

These EEG findings are so unusual that their occurrence in five individuals with overt cleidocranial-dysplasia must be more than a coincidence. Symptoms in this condition are uncommon; hence the difficulty in finding patients through hospital records unless they have a coincidental medical disorder, as with the propositus in Family 1. When symptoms occur in cleidocranial-dysplasia, they are likely to be secondary to skeletal or dental abnormalities. The commonest complaint is failure of eruption or maleruption of teeth; otherwise a patient may present with short stature, kyphosis or scoliosis, coxa vara or coxa valga. Apart from occasional deafness, symptoms related to the skull deformity are not found and there is no increased incidence of neurological problems. It is a dominantly inherited condition where sometimes manifestation of the gene is so mild that the disorder is not detected clinically. However, in such cases, there are usually radiological abnormalities. The subject is reviewed by Forland (1962), Levin and Sonnenschein (1963) and Warkany and Kirkpatrick (1969).

The EEG findings reported above in five certain heterozygotes for cleido-cranial-dysplasia are not, however, a constant feature of this condition, for there are two members in Family 2 (III 1 and III $_{4}$ ) who have normal visual responses; and also normal responses were found in three sporadic cases. Moreover, $\mathrm{III}_{7}$, in Family 1 has these large photic responses in the absence of clinical and radiological changes of cleido-cranial-dysostosis. The most likely explanation is that the large photic responses are an irregular manifestation of cleido-cranialdysplasia, and that III 7 in Family 1 is a symptomless heterozygote.

The cortical origin of the early responses recorded from the scalp over the striate and Rolandic areas has been confirmed by a comparison 
of the scalp record with records obtained directly from the cortex during neurosurgery (Jasper et al, 1960; Hirsch et al, 1961; Katzman, 1964), the difference being mainly in the amplitude of the response (Giblin, 1964).

In a skeletal disorder the importance of skull thickness must be considered in the interpretation of a scalp potential particularly as a 20 to $70 \%$ difference in the amplitude of visual evoked responses has been attributed to differences in skull thickness (Leissner, Lindholm and Petersen, 1970). It is unlikely that the large photic responses (over $320 \%$ ) are a direct result of skull thickness or an anatomical rearrangement of the occipital lobes secondary to brachycephaly and transverse widening of the skull. For III7 in Family 1 and IV 1 in Family 2 with normally shaped skulls have a large visual response; and $\mathrm{III}_{4}$ in Family 2 and two sporadic cases (L.T. and C.N.) have abnormally shaped skulls but normal visual responses. In other dysostoses where brachycephaly occurs, such unusual EEG findings have not been reported and it is unlikely that brachycephaly or skull thickness could account for the influence of frequency on response.

The amplitude of visual evoked responses is known to vary with alertness (Donchin and Lindsley, 1966) blood sugar level and fatigue (Walter, 1950) but we have no reason to think that these factors differed for our patients and controls.

It has been claimed that the late components of the usual evoked responses are larger in bright children than in dull children (Rhodes, Dustman and Beck, 1969). However, in our results, large responses were seen in III7 (D.M. b. 11.12.53) who was educationally subnormal. The responses were larger in III6 than in IIIs even though IIIs had a better academic record so we are unable to correlate our results with I.Q. estimates. Dustman and Beck (1963) found a correlation between the amplitude of the visual evoked response and age but we were unable to demonstrate this.
Large responses may result from eye movements after a flash (Alajouanine, Nehlil and Gabersek, 1959) but in our patients the amplitude of the responses was largest over the occipital regions and the frontal leads showed little response. Since lambda waves can be evoked by scanning an evenly lit text, and since the responses produced are as large as those resulting from the largest and brightest flashes (Rémond, Lesèvre and Torres, 1965) this possibility had to be considered. In Family 1, the responses to reversal of a chequerboard pattern were large but were not outside the normal limits for this laboratory. Accommodation and convergence of the eyes were unlikely to be the cause of the difference between the responses to massive flash and pattern reversal, contrary to the results of Russel, Harter and Salmon, (1971) because the flash evoked responses were unaffected when the patient focused on the lamp.

Since a large flash is likely to produce about as much inhibition as excitation (Hubel and Wiesel, 1962) it is possible that our results could be explained by an altered balance between inhibitory and excitatory mechanisms, particularly as the abnormal responses diminished with increasing frequency of stimulation. The optimal "driving" frequency in man shifts from $3 \mathrm{c} / \mathrm{sec}$ in the newborn to 8-10 c/sec by the age of 1-2 years (Vitova and Hrbek, 1970) but in our patients the maximal amplitudes of the responses to flash stimuli occurred at stimulation rates of less than $3 \mathrm{c} / \mathrm{sec}$. The number of spikes per stimulus decreases in retinal ganglion cells at higher flash rates (Grusser and Rabelo, 1959) and the number of discharges per second in afferent fibers of the optic radiation is highest at 10-15 flashes per second (Grusser and Creutzfeldt, 1971). Kuhnt and Creutzfeldt (1971) recorded from cortical neurons of area 17 of the cat and found an excitatory post synaptic potential (E.P.S.P.) followed by an inhibitory post synaptic potential (I.P.S.P.) at rates of flash stimulation below 2 per second. Above flash rates of 2 to $4 / \mathrm{sec}$ the amplitude of the I.P.S.P. diminished and it disappeared completely above stimulus frequencies of $10-15 / \mathrm{sec}$ even at the highest stimulus intensities. The E.P.S.P. is unmasked as the I.P.S.P. diminishes, but the amplitude of the E.P.S.P. decreased above stimulus frequencies of $10-12 / \mathrm{sec}$, which Kuhnt and Creutzfeldt (1971) attribute to the decreased spike rate/flash in the afferent fibers of the optic radiation. Clearly our results could be explained by a diminished I.P.S.P. or an unusually large E.P.S.P. at low stimulus rates. As the patient $\mathrm{II}_{6}$ in Family 1 died in his third epileptic attack it is interesting to speculate about a disturbance of inhibitory mechanisms which may be important in the genesis of epilepsy (Jung and Tonnies, 1950; Eccles, 1969).

The patient with the largest photic responses (E.M. III6) in Family 1 was the only epileptic in our series, but visual evoked potentials have been reported to be diminished in amplitude in epileptics (Cernaceck and Ciganek, 1964). Jonkmann (1967) found no difference between normals and epileptics. An increase in normal evoked potentials in photogenic epileptics and other epileptic groups has been described (Halliday, 1967). Creutzfeldt and Heinemann (1970) found that different types of epilepsy could not be distinguished by the visual evoked responses at low rates of stimulation and they also found visual evoked responses in two patients suffering from photogenic epilepsy. There is no evidence that any of our patients suffered from photogenic epilepsy and no myoclonic jerks or spikes and waves were seen in the EEG's of any of the patients during photic stimulation. Such responses would be unusual at the low rates of stimulation which produced the large responses in our group.

\section{ACKNOWLEDGEMENTS}

We are extremely grateful to $\mathrm{Mr}$. $\mathrm{H}$. B. Morton for carrying out the pattern evoked visual responses in the five patients.

We should like also to thank Dr. W. A. Cobb and Mr. J. W. Osselton, for their guidance in the preparation of this manuscript; and Professor Gilliatt, Professor G. R. Seward and Mr. P. M. O'Driscoll for allowing us to study patients under their care. 


\section{REFERENCES}

ADRIAN, E. D. and MATTHEWS, B. H. C. (1934). The Berger Rhythm: Potential Changes from the Occipital Lobes in Man. Brain, 57: 355.

ALAJOUANINE, T., NEHLIL, J., and GABERSEK, V. (1959). A propos d'une cas d'epilepsie declenche par la lecture. Revue Neurologique, 101: 463-467.

CERNACECK, J. and CIGANEK, L. (1962). The Cortical Electroencephalographic Response to Light Stimulation in Epilepsy. Epilepsia (Amst.), 3: 303-314.

COBB, W. A. and DAWSON (1960). The Form and Latency in Man of the Occipital Potentials Evoked by Bright Flashes. Journal of Physiology (London), 152: 108-121.

COBB, W. A., ETTLINGER, G. and MORTON, H. B. (1968). Cerebral Potentials Evoked in Man by Pattern Reversal and their Suppression in Visual Rivalry. Journal of Physiology (Lond.), 195: 33-34P.

DONCHIN, E. and LINDSLEY, D. B. (1966). Averaged evoked potentials and reaction times to visual stimuli. Electroencephalography and Clinical Neurophysiology, 20: 217-223.

DUSTMAN, R. E. and BECK, E. C. (1966). Visual Evoked Potentials. Amplitude Changes with Age. Science, 151:1013-1015.

DUSTMAN, R. E. and BECK, E. C. (1969). The Effects of Maturation on the Wave Form of Visually Evoked Potentials. Electroencephalography and Clinical Neurophysiology, 26: 2-11.

ECCLES, J. C. (1969). Excitatory and Inhibatory Mechanisms in the Brain. In $\mathrm{H}$. $\mathrm{H}$. Jasper et al. (Eds.), Basic Mechanism of the Epilepsies. Little, Brown, Boston: 229-252.

FENWICK, P. B. C. and DOLLIMORE, J. (1969). Mathematical Model Providing a Synthesis between Evoked and Spontaneous Phenomena of the EEG. Electroencephalography and Clinical Neurophysiology. Supp. 2: 60 .

FORLAND, M. (1962). Cleido-Cranial Dysostosis. American Journal of Medicine, 33: 792-799.

GIBLIN, D. R. (1964). Somatosensory Evoked Potentials in Healthy Subjects and in Patients with Lesions of the Nervous System. Annals of the New York Academy of Science, 112: 93-142.

GRUSSER, $O$. J. and CREUTZFELDT, $O$. (1957). Maxima der Impulsfrequenz Retinaler und Corticaler Neurone bei Flimmerlight Mittlerer Frequenzen Pflugers Arch. Ges. Physiol., 263: 668-681.

GRUSSER, O. J. and REBELO, C. (1959). Die Wirkung von Flimmerreizen mit Lichtbutzen an Einselnen Corticalen Neuronen. I.V. Int. EEG Congr., Brussels. Pergamon, London, 371-375.
HALLIDAY, A. M. (1965). Cerebral Evoked Potentials in Familial Progressive Myoclonus Epilepsy. Journal Royal College of Physicians, London, 1: 123-134.

HIRSCH, J. F., PERTUISET, B., CALVET, J., BUISSON-FEREY, J., FISCHGOLD, H. et SCHERRER, J. (1961). Etude des responses electrocorticales obtenues chez l'homme par des stimulations somesthetiques et visuelles. Electroencephalography and Clinical Neurophysiology, 13: 411-424.

HUBEL, D. H. and WIESEL, T. N. (1971). Receptive Fields of Convergence and Accommodation on Visually Evoked Cortical Responses and Visual Acuity. Electroencephalography and Clinical Neurophysiology, 31: 287-288.

JASPER, J., LENDE, R. and RASMUSSEN, T. (1960). Evoked Potentials from the Exposed Somatosensory Cortex in Man. Journal of Nervous and Mental Diseases, 130: 526-537.

JONKMANN, E. J. (1967). The Average Cortical Response to Photic Stimulation. Doctoral Thesis. University of Amsterdam, 160p.

JUNG, R., and TONNIES, J.' F. (1950). Hirnelektrische Untersuchung uber Enstehung und Erhaltung von Krampfentladungen. Arch. Psychiat. Nervenkr., 185: 701-735.

KATZMAN, R. (1964). The Validity of the Visual Evoked Response in Man. Annals of the New York Academy of Science, 112: 238-240.

KOLOH, L. G. and OSSELTON, J. W. (1966). Clinical Electroencephalography. 2nd Edition, London. Butterworths.

KOOI, K. A. and BAGCHI, B. K. (1964). Visual Evoked Responses in Man: Normative Data. Annals of the New York Academy of Science, 112: 254-269.

KUHNT, U. and CREUTZFELDT, D. D. (1971). Decreased Postsynaptic Inhibition in the Visual Cortex during Flicker Stimulation. Electroencephalography and Clinical Neurophysiology, 30: 79-82.

LEISSNER, P., LINDHOLM, L. E., and PETERSEN, I. (1970). Alpha Amplitude Dependence on Skull Thickness as Measured by Ultrasound Technique. Electroencephalography and Clinical Neurophysiology, 29: 392-399.

LEVIN, E. J., SONNENSCHEIN, H. (1963). Cleido-Cranial-Dysostosis. New York State Journal of Medicine, 63: 1562-1566.

LUCKING, C. H., CREUTZFELDT, O. D. and HEINEMANN, U. (1970). Visual Evoked Potentials of Patients with Epi- lepsy and of a Control Group. Electroencephalography and Clinical Neurophysiology, 29: 557-566.

MOROCUTTI, C., SOMMER-SMITH, J. and CREUTZFELDT, O. D. (1966). Das Visuelle Reaktionspontential bei Normalen Versuchspersonen und Characteristische Veranderungen bei Epileptikern. Archives Psychiat., Nervenkr. 208: 234-254.

PAMPIGLIONE, G. and LEHOVSKY, M. (1968). The Evolution of EEG Features in 26 Children with Proven Neuronal Lipidosis. Electroencephalography and Clinical Neurophysiology, 25: 508.

PENROSE, L. S. (1963). The Biology of Mental Defect. Published by Sidgwick and Jackson, London.

REIGER, H., LESÈVRE, N., RÉMOND, A., and LAIRY, G. D. (1970). Responses evoquees visuelles chez les enfants voyants et mal noyants. Electroencephalography and Clinical Neurophysiology, 28: 437-448.

REMOND, A., LESËVRE, N. and TORRES, F. (1965). Etude Chronotoporgraphique de l'activite occipitale moyenne receullie sur le scalp chez l'homme en relation avec les deplacements due regard (complex Lambda). Revue Neurologique, 113: $193-226$

RHODES, L. E., DUSTMAN, R. E. and BECK, E. C. (1969). The Visual Evoked Response: A Comparison of Bright and Dull Children. Electroencephalography and Clinical Neurophysiology, 27: 364-372.

RICHARDS, B. W. (1969). Personal Communication.

RUSSELL HARTER, M. and SALMON, L. E. (1971). Effects of Convergence and Accommodation on Visually Evoked Responses and Visual Acuity. Electroencephalography and Clinical Neurophysiology, 31: 287-288.

VITOVA, Z. and HRBEK, A. (1970). Ontogeny of Photic Driving in Infants. Electroencephalography and Clinical Neurophysiology, 28: 391-398.

WALTER, W. G. (1950). The Functions of Electrical Rythm in the Brain. Journal of Mental Science, 96: 1.

WALTER, W. G. (1951). The Effect of Physical Stimuli on the EEG. Electroencephalography and Clinical Neurophysiology, Supp. 2, 60.

WARKANY, J., KIRKPATRICK, J. A. (1969) in Textbook of Pediatrics. Nelson, W. E., Vaughan, V. C., McKay, R. J., W. B. Saunders, Toronto.

WEINMAN, H., CREUTZFELDT, O. D. and HEYDE, G. (1965). Die Entwicklung der Visuellen Reizantwort bei Kindern. Archives Psychiat. Nervenkr, 207: 323-341. 